\title{
Solubility and Density of Silver Iodide in Water and DMF at Various Temperatures as Function of Potassium Iodide.
}

\author{
*U P Shinde ${ }^{1} \mathrm{H} \mathrm{S}$ Aher ${ }^{2} \mathrm{~T}_{\mathrm{B}}$ Pawar $^{2}$ \\ 1Dept. of Physics and Electronic Science L. V. H. College, Panchavati, Nashik-422003 \\ Dist- Nashik (M.S.) India \\ 2Dept. of Chemistry L. V. H. College, Panchavati, Nashik-422003 Dist-Nashik (M.S.) India
}

\begin{abstract}
The solubility of silver iodide (AgI) in water, dimethyl formamide (DMF), KI + Water, and KI + $D M F$ were measured using an analytical gravimetric method at temperatures ranging from (298.15 to 315.15) $K$. The densities of the saturated solutions are also reported. The results are interpreted in the form of enthalpy change $\Delta H$.
\end{abstract}

Keywords: Silver iodide, solubility, density, potassium iodide, molar enthalpy, molar entropy, Gibbs energy.

\section{Introduction}

AgI used for cloud seeding [1]. Solubility studies of electrolytes have applications in diverse fields such as the pharmaceutical industry, agriculture, biology, medicine, etc [2]. Solubility data for many inorganic salts in aqueous systems are available [3-5]. However there is no data available for solubility of silver iodide in presence of potassium iodide as additive. Therefore we have undertaken measurements of solubility and densities of silver iodide in presence of potassium iodide at various percentage of KI in Water and DMF at various temperatures. The thermodynamic functions of solution of AgI were calculated by using Van't Hoff equation.

\section{Materials And Methods}

The apparatus and procedures used for solubility and density measurement have been described earlier [6-8]. An excess amount of AgI was added to the KI binary solvents mixtures prepared by weight (Shimadzu, Auxzzo) with an uncertainty of $\pm 0.1 \mathrm{mg}$, in a specially designed $100 \mathrm{~mL}$ double jacketed flask. Water was circulated at constant temperature between the outer and inner walls of the flask. The temperature of the circulating water was controlled by thermostat to within $( \pm 0.1) \mathrm{K}$. The solution was continuously stirred using a magnetic stirrer for long time (about $1 \mathrm{~h}$ ) so that equilibrium is assured, no further solute dissolved, and the temperature of solution is same as that of circulating water; the stirrer was switched off; and the solution was allowed to stand for $1 \mathrm{~h}$. Then a fixed quantity of the supernatant liquid was withdrawn from the flask in a weighing bottle with the help of pipet which is hotter than the solution. The weight of this sample was taken and the sample was kept in an oven at $343 \mathrm{~K}$ until the whole solvent was evaporated and the residue was completely dry. This was confirmed by weighing two or three times until a constant weight was obtained after keeping the sample in an oven for another 30 min every time. The solubility has been calculated using weight of solute and weight of solution. The saturated mole fraction solubility was calculated using usual equations. Densities were determined using a $15 \mathrm{~cm}^{3}$ bicapillary pycnometer. For calibration of pycnometer triply distilled and degassed water with a density of $0.99705 \mathrm{~g} \cdot \mathrm{cm}^{-3}$ at $298.15 \mathrm{~K}$ was used. The pycnometer filled with air bubble free experimental liquids was kept in a transparent walled thermostat (maintained at constant temperature $\pm 0.1 \mathrm{~K}$ ) for (10 to 15) min to attain thermal equilibrium. The heights of the liquid levels in the two arms were measured with the help of a traveling microscope, which could read to $0.01 \mathrm{~mm}$.

III. Figures And Tables

Table 1: Mole fraction solubility (X) of AgI in KI + Water and KI + DMF solvent.

\begin{tabular}{|c|c|c|c|c|c|}
\hline \multicolumn{7}{|c|}{ AgI+KI-Water } \\
\hline Temp $\left({ }^{\circ} \mathrm{K}\right)$ & $1 \% \mathrm{KI}$ & $2 \% \mathrm{KI}$ & $3 \% \mathrm{KI}$ & $4 \% \mathrm{KI}$ & $5 \% \mathrm{KI}$ \\
\hline 298.15 & $1.68 \mathrm{E}-05$ & $2.69 \mathrm{E}-05$ & $9.44 \mathrm{E}-05$ & 0.00019 & 0.00029 \\
\hline 303.15 & $6.61 \mathrm{E}-05$ & $6.69 \mathrm{E}-05$ & 0.00011 & 0.00017 & 0.00025 \\
\hline 308.15 & 0.00010 & $8.00 \mathrm{E}-05$ & 0.00014 & 0.00023 & 0.00028 \\
\hline 315.15 & $2.30 \mathrm{E}-04$ & $6.21 \mathrm{E}-05$ & 0.00016 & 0.00022 & 0.00030 \\
\hline \multicolumn{7}{|c|}{ AgI+KI-DMF } \\
\hline Temp $\left({ }^{\circ} \mathrm{K}\right)$ & $0.1 \% \mathrm{KI}$ & $0.2 \% \mathrm{KI}$ & $0.3 \% \mathrm{KI}$ & $0.4 \mathrm{KI}$ & $0.5 \% \mathrm{KI}$ \\
\hline 298.15 & 0.0009 & 0.00234 & 0.00264 & 0.00335 & 0.00290 \\
\hline 303.15 & 0.0010 & 0.00237 & 0.00326 & 0.00372 & 0.00353 \\
\hline 308.15 & 0.0011 & 0.00234 & 0.00354 & 0.00388 & 0.00548 \\
\hline 315.15 & 0.0011 & 0.00257 & 0.00352 & 0.00398 & 0.00643 \\
\hline
\end{tabular}


Solubility and density of Silver iodide in water and DMF at various temperatures...

Table 2: Densities of saturated solution of $\mathrm{AgI}$ in $\mathrm{KI}+$ Water and $\mathrm{KI}+\mathrm{DMF}$ solvent

\begin{tabular}{|c|c|c|c|c|}
\hline \multirow{2}{*}{ Amount of KI taken } & \multicolumn{4}{|c|}{$\rho$ AgI+KI-Water } \\
\cline { 2 - 5 } & 298.15 & 303.15 & 308.15 & 313.15 \\
\hline $1 \% \mathrm{KI}$ & 1.0035 & 1.0030 & 1.0018 & 1.0004 \\
\hline $2 \% \mathrm{KI}$ & 1.0117 & 1.0108 & 1.0094 & 1.0080 \\
\hline $3 \% \mathrm{KI}$ & 1.0191 & 1.0176 & 1.0162 & 1.0155 \\
\hline $4 \% \mathrm{KI}$ & 1.0259 & 1.0251 & 1.0237 & 1.0223 \\
\hline $5 \% \mathrm{KI}$ & 1.0337 & 1.0325 & 1.0312 & 1.0299 \\
\hline \multirow{2}{*}{ Amount of KI taken } & \multicolumn{5}{|c|}{$\rho \mathrm{AgI}+\mathrm{KI}-\mathrm{DMF}$} \\
\cline { 2 - 5 } & 298.15 & 303.15 & 308.15 & 313.15 \\
\hline $0.1 \% \mathrm{KI}$ & 0.9473 & 0.9435 & 0.9406 & 0.9383 \\
\hline $0.2 \% \mathrm{KI}$ & 0.9513 & 0.9476 & 0.9444 & 0.9395 \\
\hline $0.3 \% \mathrm{KI}$ & 0.9521 & 0.9517 & 0.948 & 0.9465 \\
\hline $0.4 \% \mathrm{KI}$ & 0.9548 & 0.9527 & 0.9495 & 0.948 \\
\hline $0.5 \% \mathrm{KI}$ & 0.9562 & 0.9537 & 0.951 & 0.9487 \\
\hline
\end{tabular}

Table 3: Thermodynamic Functions Relative to Solution Process of AgI at Tmean $=305.65 \mathrm{~K}$

\begin{tabular}{|c|c|c|c|c|c|}
\hline composition & $\begin{array}{c}\Delta \mathrm{H}\left(\mathrm{KJK}^{-}\right. \\
\left.{ }^{1} \mathrm{~mol}^{-1}\right)\end{array}$ & $\Delta \mathrm{G}\left(\mathrm{KJK}^{-1} \mathrm{~mol}^{-1}\right)$ & $\Delta \mathrm{S}_{\left(\mathrm{KJK}^{-1} \mathrm{~mol}^{-1}\right)}$ & $\begin{array}{c}\Delta \mathrm{S}^{\left(\mathrm{JK}^{-1} \mathrm{~mol}^{-}\right.} \\
)\end{array}$ & $\mathrm{T} \Delta \mathrm{S}\left(\mathrm{KJK}^{-1} \mathrm{~mol}^{-1}\right)$ \\
\hline $1 \% \mathrm{KI}$ & 8.1809 & 24.0360 & -0.0518 & -51.8731 & -15.8550 \\
\hline $2 \% \mathrm{KI}$ & 42.3930 & 24.9143 & 0.0571 & 57.1854 & 17.4787 \\
\hline $3 \% \mathrm{KI}$ & 30.3544 & 22.7802 & 0.0247 & 24.7805 & 7.5741 \\
\hline $4 \% \mathrm{KI}$ & 11.7975 & 21.5668 & -0.0319 & -31.9623 & -9.7692 \\
\hline $5 \% \mathrm{KI}$ & 2.9930 & 20.7446 & -0.0580 & -58.0782 & -17.7516 \\
\hline \multicolumn{5}{|c|}{ AgI+KI-DMF } \\
\hline $0.1 \% \mathrm{KI}$ & 3.0928 & 17.2963 & -0.0464 & -46.4698 & -14.2035 \\
\hline $0.2 \% \mathrm{KI}$ & 4.1736 & 15.3117 & -0.0364 & -36.4409 & -11.1381 \\
\hline $0.3 \% \mathrm{KI}$ & 14.7739 & 14.5688 & 0.00067 & 0.6711 & 0.2051 \\
\hline $0.4 \% \mathrm{KI}$ & 11.1407 & 14.1644 & -0.0098 & -9.8926 & -3.0236 \\
\hline $0.5 \% \mathrm{KI}$ & 43.9311 & 13.79 & 0.0986 & 98.6131 & 30.1411 \\
\hline
\end{tabular}

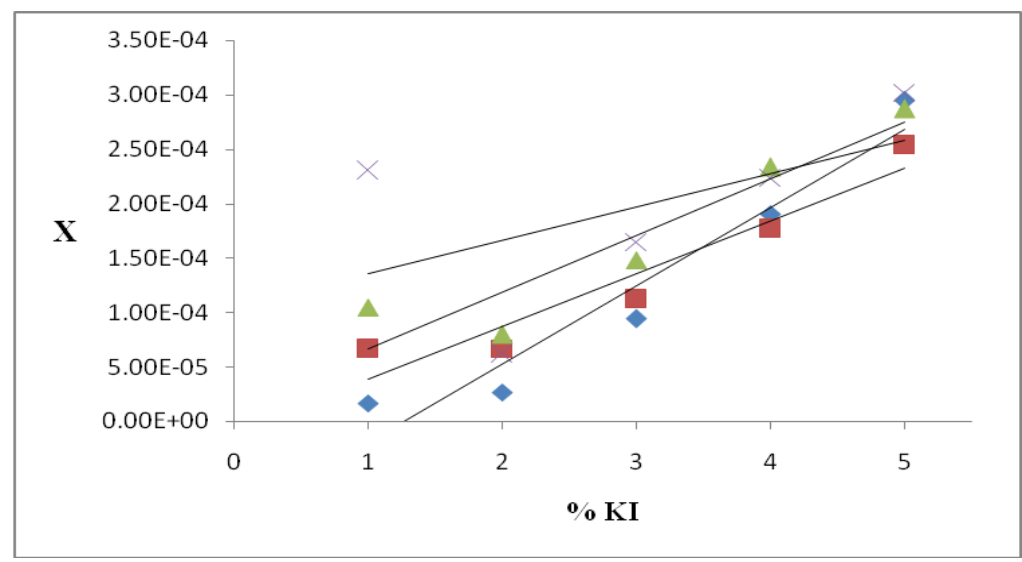

Fig 1: Variation of Mole fraction solubility (X) of AgI with \% of KI in KI+ water solvent mixture. 


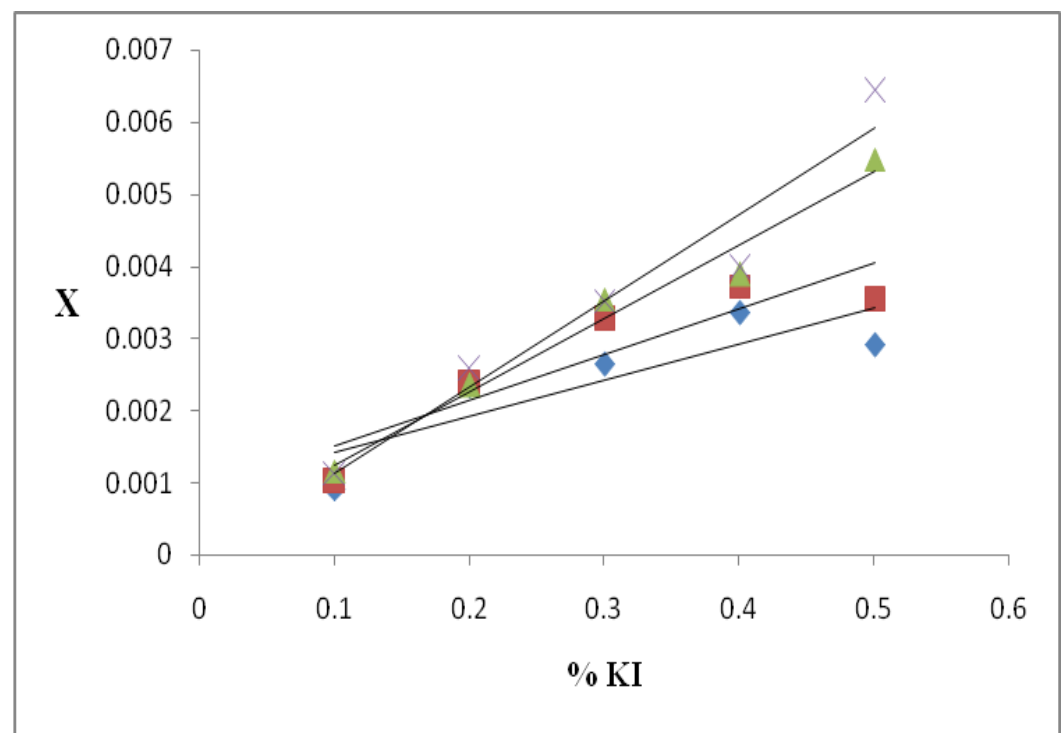

Fig 2: Variation of Mole fraction solubility (X) of AgI with \% of KI in KI+ DMF solvent mixture.

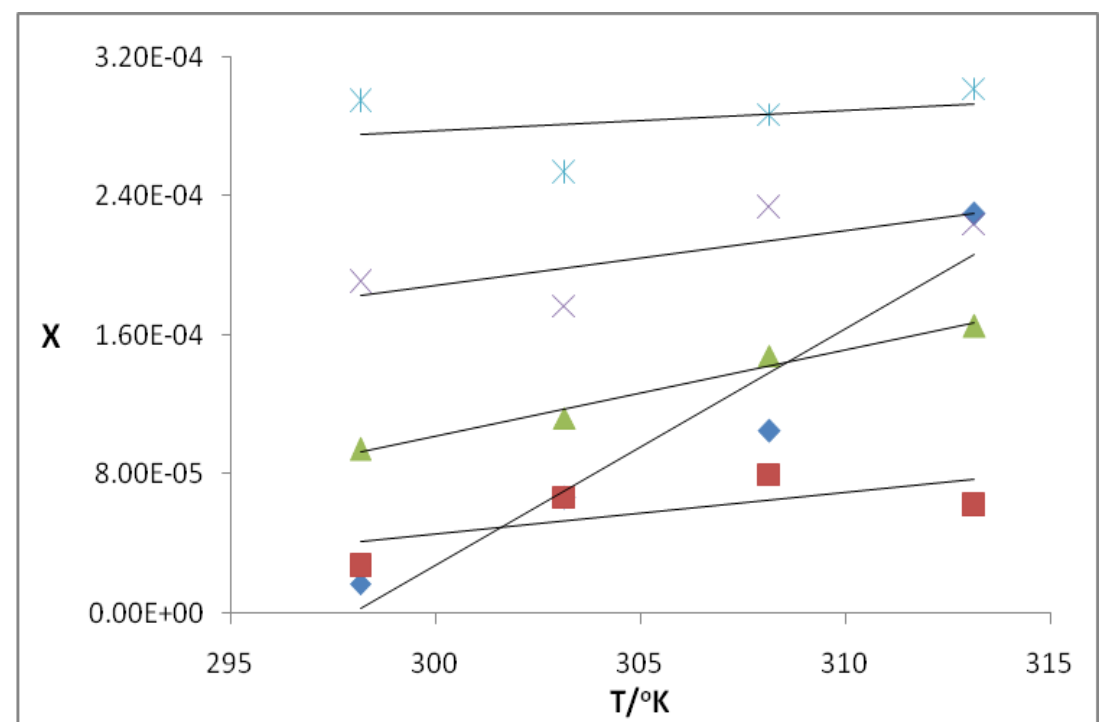

Fig 3:- Mole fraction solubility (X) of AgI in KI + Water solvent with temperature.

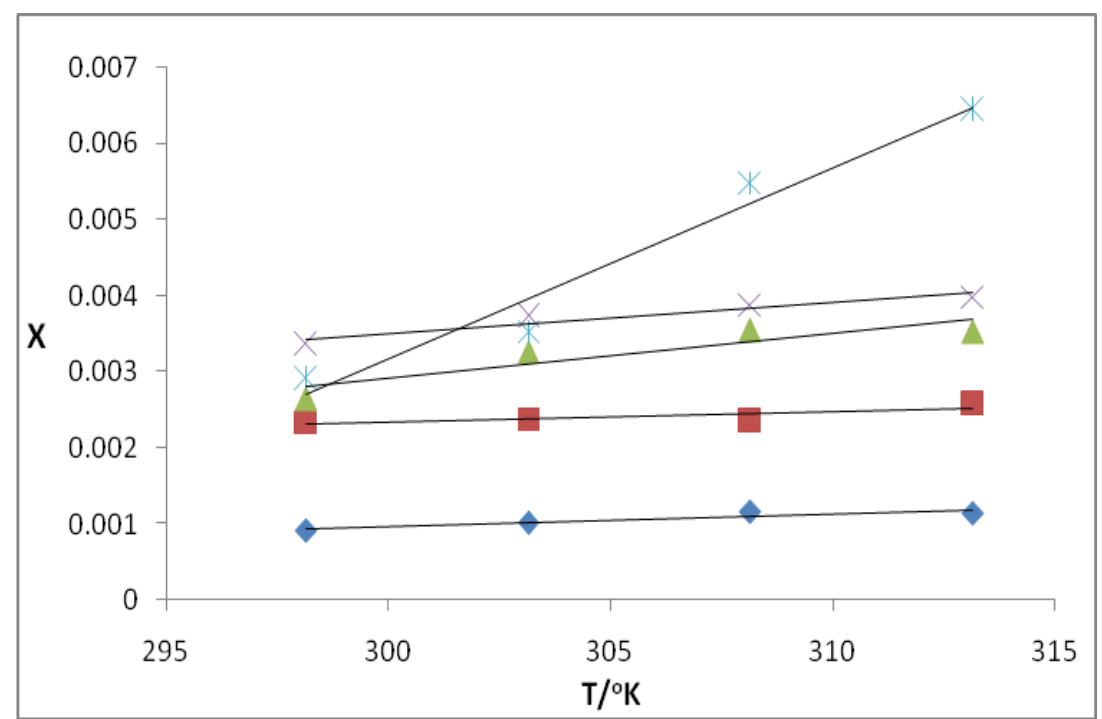

Fig 4:- Mole fraction solubility (X) of AgI in KI + DMF solvent with temperature. 


\section{Results And Discussion}

The experimental values of solubility (X) and density $(\rho)$ of the saturated solutions at $(298.15,303.15$, 308.15, and 315.15) ${ }^{\circ} \mathrm{K}$ for $\mathrm{AgI}+\mathrm{KI}$ in water and DMF are given in Tables $1 \& 2$ respectively. Variation of solubility with composition of KI and that of with temperature in water and DMF are shown in Figures 1 to 4. It can be seen that the solubility of $\mathrm{AgI}$ in both $\mathrm{KI}+$ Water and $\mathrm{KI}+$ DMF mixtures increases with increasing content of KI in solvent mixtures. It can also be seen that the solubility of AgI in KI + Water and KI + DMF mixtures with given initial compositions increases with temperature. But increment of solubility is higher with $\%$ of KI as compared to the temperature which can be seen from graph. These indicate that KI is found to be very important additive for increasing solubility of AgI. Solubility of AgI was found to be higher in KI+DMF solvent. The density of saturated solution of AgI in both KI + Water and KI + DMF mixtures is found to decrease with temperature. But density is found to increase with \% KI which is usual one.

Thermodynamic functions of solution are important to study the dissolution behavior of the solute in different solvents. The temperature dependence of the solubility allows a thermodynamic analysis that permits insight into the molecular mechanisms involved in the solution processes. In this work the thermodynamic functions in the process of solution of $\mathrm{AgI}$ are calculated on the basis of the solubility of $\mathrm{AgI}$ in different solvents. According to the van't Hoff equation, the standard molar enthalpy change of solution $\Delta \mathrm{H}$ is generally obtained from the slope and standard molar Gibbs energy change for the solution process $\Delta \mathrm{G}$ is obtained from the intercept of the $\ln \mathrm{X}$ vs 10000 (1/T - 1/Tmean) plot in the way similar to Pawar et al. [9].

Average temperature Tmean is introduced to obtain a single value of $\Delta \mathrm{G}$ and $\Delta \mathrm{S}$ in the temperature range studied. In the present work, Tmean $=305.65 \mathrm{~K}$ and the temperature range is $(298.15$ to 313.15$) \mathrm{K}$. The standard molar entropy change $\Delta \mathrm{S}$ is obtained from eq. as $\Delta \mathrm{S}=[(\Delta \mathrm{H}-\Delta \mathrm{G}) /$ Tmean]. Results are shown in Table 3. From Table 3 it can be concluded that the standard Gibbs free energy of silver iodide is positive in all the studied system as is the enthalpy of solution. Therefore the process is always endothermic and the entropy of solution is negative for $\mathrm{AgI}$ in $\mathrm{KI}+$ water system while enthalpy is positive, it means enthalpy is the driving force for the systems. For all systems, the main contributor to the positive standard molar Gibbs energy of silver iodide solution is the enthalpy.

\section{Conclusion}

The solubility of $\mathrm{AgI}$ in all solvent system was found to increase with increasing content of additive KI. So KI plays very important role to increase solubility. Also solubility of AgI increases with increasing temperature in all studied systems. The solution process is always endothermic. For all systems the main contributor to the positive standard molar Gibbs energy of silver iodide solution is the enthalpy.

\section{Acknowledgement}

The authors greatly thanks to the management authorities of M. G. Vidyamandir, the Principal of L.V. H. Arts, Science and Commerce College, Panchavati Nashik for giving valuable support to do this work.

\section{References}

[1]. Phyllis A. Lyday "Iodine and Iodine Compounds" in Ullmann's Encyclopedia of Industrial Chemistry, Wiley-VCH, Weinheim, 2005.

[2]. J A F Lozano, Recovery of Potassium Magnesium Sulfate Double Salt from Seawater Bittern. Ind. Eng. Chem. Process Des. Dev. 1976, 15, 445-447.

[3]. H Stephan, T Stephan, Solubilities of Inorganic and Organic Compounds, vol-1, Binary Systems; Part-1; Eds. Pergamon Press: Oxford, England, 1963; p 110.

[4]. J A Dean, Langes Handbook of Chemistry, 13th ed.; McGraw-Hill: New York, 1987; p -10.

[5]. D R Lide, CRC Handbook of Chemistry and Physics, 79th ed.; CRC Press: Boca Raton, FL, pp 8-108.

[6]. R R Pawar, S B Nahire, M Hasan, Solubility and Density of Potassium Iodide in Binary Ethanol-Water Solvent Mixture at (298.15, 303.15, 308.15, and 313.15) K. J. Chem. Eng. Data 2009, 54, 1935-1937.

[7]. U B Kadam, A R Hiray, A B Sawant, M Hasan, Density, Viscosities, and Ultrasonic Velocity Studies of Binary Mixtures of Chloroform with Propan-1-ol and Butan-1-ol at (303.15 and 313.150), K. J. Chem. Eng. Data 2006, 51, 60-63.

[8]. M Hasan, D F Shirude, A R Hiray, U B Kadam, A B Sawant, Densities, Viscosities and Speed of Sound Studies of Binary Mixtures of Methylbenzene with Heptan-1-ol, Octan-1-ol and Decan-1-ol at (303.15 and 313.15), K. J. Chem. Eng. Data 2006, 51, $1922-26$.

[9]. Ramesh R. Pawar, Chandrakant S. Aher, Jitendra D. Pagar, Sonali L. Nikam, and Mehdi Hasan, Solubility, Density and Solution Thermodynamics of NaI in Different Pure Solvents and Binary Mixtures, J. Chem. Eng. Data 2012, 57, 3563-3572.

IOSR Journal of Applied Physics (IOSR-JAP) is UGC approved Journal with S1. No. 5010, Journal no. 49054.

U P Shinde. "Solubility and Density of Silver Iodide in Water and DMF at Various Temperatures as

Function of Potassium Iodide." IOSR Journal of Applied Physics (IOSR-JAP) 9.4 (2017): 64-67. 